\title{
Water Relations of Salmonella oranienburg: Accumulation of Potassium and Amino Acids during Respiration
}

\author{
By J. H. B. CHRISTIAN AND JANICE M. HALL \\ Commonwealth Scientific and Industrial Research Organization, \\ Division of Food Research, North Ryde, N.S.W., Australia 2 I 13 \\ (Accepted for publication 3 December I97I)
}

\begin{abstract}
SUMMARY
Potassium and ${ }^{14} \mathrm{C}$-labelled proline, aspartic acid, glutamic acid, and alanine were accumulated by Salmonella oranienburg, during glucose oxidation, over a range of water activity $\left(a_{w}\right)$ values. In the absence of amino acids, potassium accumulation increased to a maximum as $a_{\mathrm{w}}$ was decreased to about 0.975 but then dropped to a low value at $0.960 a_{\mathrm{w}}$; with an amino acid, potassium accumulation was much increased and maximum uptake occurred at $0.960 a_{\mathrm{w}} \cdot\left[{ }^{14} \mathrm{C}\right]$ Proline uptake increased linearly with decrease in $a_{\mathrm{w}}$, the accumulated proline being metabolized in part to glutamic acid and to deaminated compounds; at $0.95 a_{\mathrm{w}}$ uptake of $\left[{ }^{14} \mathrm{C}\right]-$ proline reached $\mathrm{I} \cdot 4 \mathrm{mmol} / \mathrm{g}$ dry bacteria. Uptake of aspartate was comparable to that of proline at $a_{\mathrm{w}}$ down to 0.98 but then decreased. Relatively little exogenously supplied glutamate or alanine was accumulated at any water activity. At $a_{\mathrm{w}}$ levels below 0.98 , oxygen uptake by non-growing bacterial suspensions increased with time and accompanied the linear uptake of proline. Proline accumulation ceased when a maximum rate of oxygen consumption was reached. At 0.97 $a_{\text {w }}$ the rate of proline uptake was unaffected by a mixture of 19 amino acids, but the total proline uptake decreased to one-half. In contrast, the proline homologue azetidine-2-carboxylic acid lowered the rate and extent of proline accumulation by one-third.
\end{abstract}

\section{INTRODUCTION}

The nutritive status of the environment affects markedly the ability of Salmonella oranienburg to grow at low levels of water activity $\left(a_{w}\right)$. Particularly important are several amino acids, of which proline is essential for growth at $a_{\mathrm{w}}$ below 0.97 (Christian, 1955). Proline stimulates respiration of this organism at low $a_{w}$ levels to a far greater extent than do other amino acids, and substantially increases intracellular levels of potassium, proline and total amino acids (Christian \& Waltho, 1966). Lowered $a_{\mathrm{w}}$ also affects accumulation of potassium (Epstein \& Schultz, I965) and of proline (Britten \& McClure, I962) by Escherichia coli.

Proline may stimulate respiration at low $a_{\mathrm{w}}$ by overcoming the effects of shrinkage or plasmolysis (Christian \& Waltho, 1966); by promoting accumulation of high levels of osmotically active ions and molecules within the organism. The present paper reports the influence of $a_{w}$ on the rate and extent of potassium and amino acid uptake, and their relation to respiratory stimulation. The amino acids studied were those giving high (proline), moderate (aspartic acid), slight (glutamic acid), and negligible (alanine) stimulation of glucose respiration at $0.97 a_{\mathrm{w}}$. 


\section{METHODS}

Organisms and growth conditions. Salmonella oranienburg and, for comparison, Staphylococcus aureus were grown in brain-heart $(\mathrm{BH})$ broth $\left(0.993 a_{\mathrm{w}}\right)$, at $30^{\circ}$, with shaking, as described previously (Christian \& Waltho, I964, I966).

Uptake experiments. Bacterial suspensions, reaction mixtures and bacterial dry weights were prepared or determined as described by Christian \& Waltho (I966). Briefly, early stationary phase organisms were washed twice in Na-K-phosphate buffer ( $0.1 \mathrm{M}, \mathrm{pH} 7 \cdot 0$; potassium concentration $13.3 \mathrm{mM}$ ) and suspended in this buffer containing glucose $(3.3 \mathrm{~mm})$. Oxygen consumption and (usually) potassium and amino acid accumulation were measured in conventional Warburg equipment. In some experiments, solute uptake was studied in test-tube cultures aerated through capillary tubing. In some studies of proline accumulation, glucose was omitted. Unless otherwise noted, each amino acid (L-isomer) was at I.67 mM. The $a_{w}$ was adjusted with $\mathrm{NaCl}$ and experiments were performed at $30^{\circ}$ with $100 \mu \mathrm{g}$ chloramphenicol $/ \mathrm{ml}$ to permit comparison with earlier respiration studies (Christian \& Waltho, 1966).

To measure solute accumulation, samples of the reaction mixture were transferred at intervals to membrane filters, filtered by suction and washed twice in $\mathrm{NaCl}$ isotonic with the reaction mixture. For potassium determinations, the wet organisms and membrane filters were extracted at room temperature with $0 . \mathrm{I} \mathrm{N}-\mathrm{HCl}$ and the extract analysed by flame photometry. For the assay of radioactive amino acids, filters were dried and the activity determined by liquid scintillation counting. Uniformly ${ }^{14} \mathrm{C}$-labelled L-alanine, L-aspartic acid, L-glutamic acid and L-proline were obtained from the Radiochemical Centre, Amersham, Buckinghamshire. The data for accumulation of solutes do not include the amounts initially present (i.e. potassium 354 , total amino acids $\mathrm{I} 69$ and proline $\mathrm{I} \mu \mathrm{mol} / \mathrm{g}$ dry wt organisms) (Christian \& Waltho, I966).

The extent of metabolism of proline during accumulation at $0.97 a_{\mathrm{w}}$ was followed chromatographically. Duplicate $3 \mathrm{ml}$ samples of the bacterial suspension were taken at intervals, washed twice with $0.97 a_{\mathrm{w}} \mathrm{NaCl}$ solution and extracted by boiling with $0.17 \mathrm{~N}-$ acetic acid. Each extract was combined with the supernatant fluid from a further acid washing, dried in vacuo and subsequently chromatographed on Whatman no. I paper in $n$-butanol:acetic acid:water (4:I:I by volume). Amino acid spots were located with ninhydrin and identified from standard mixtures run in parallel. The paper was cut into segments and the radioactivity of the separated amino acids, and of the original concentrate, determined by liquid scintillation counting.

\section{RESULTS}

\section{Relationship between respiration and solute accumulation}

The results of two experiments at $0.97 a_{\mathrm{w}}$ are shown in Fig. I. In the absence of proline, respiration rate increased for nearly $100 \mathrm{~min}$ before approaching linearity while the rate of potassium accumulation was constant. Potassium accumulation ceased when a maximum respiration rate was reached. Proline greatly stimulated uptakes of both oxygen and potassium. The respiratory lag was much decreased and the potassium pool much increased, but potassium accumulation again ceased at the maximum respiration rate. There was a rapid and linear accumulation of proline and its metabolic products which also reached its maximum after $45 \mathrm{~min}$. The similarity between the times taken for formation of the potassium pool and of the ${ }^{14} \mathrm{C}$ pool from proline was fortuitous; at $a_{\mathrm{w}}<0.97$ the 


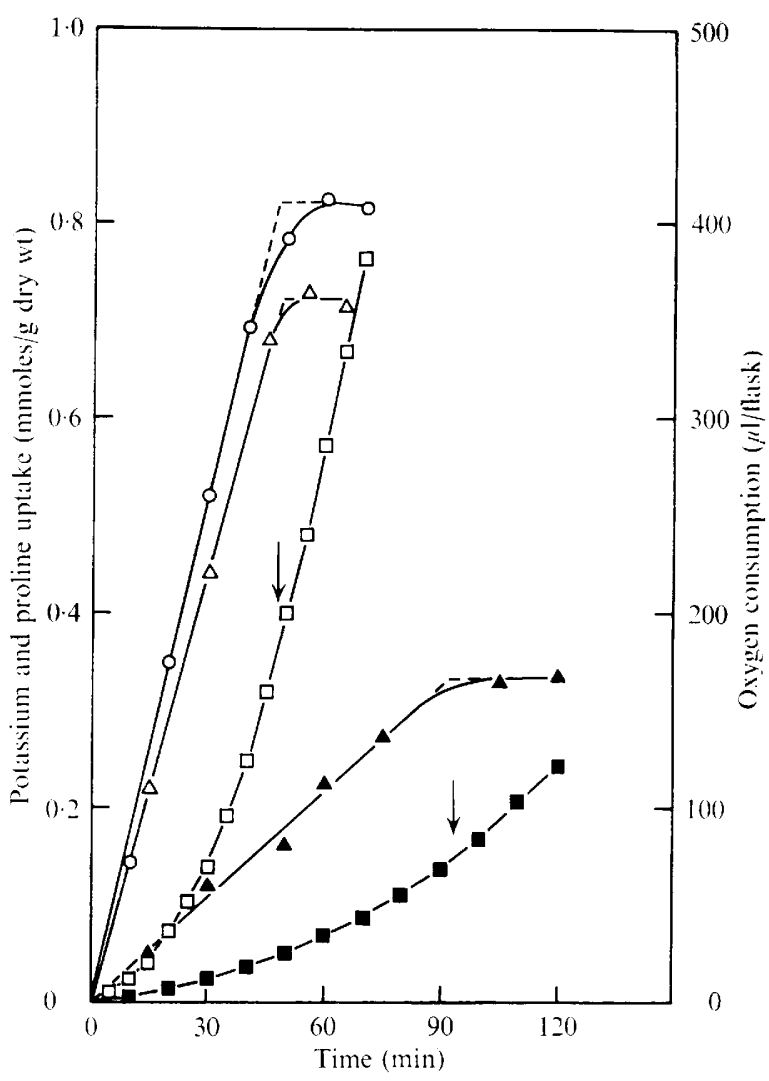

Fig. I. Uptake of oxygen, potassium and $\left[{ }^{14} \mathrm{C}\right]$ proline by Salmonella oranienburg during respiration at $0.97 a_{\mathrm{w}}$. $\bigcirc$, Proline; $\Delta$, potassium (with proline present); $\boldsymbol{\Delta}$, potassium (proline absent); $\square$, oxygen (with proline present); $\mathbf{n}$, oxygen (proline absent). Glucose was the primary substrate. Arrows show the onset of constant respiration rates.

${ }^{14} \mathrm{C}$ pool was completed well before that of potassium, and maximum proline uptake coincided with the onset of constant respiration rate.

\section{Water relations of potassium accumulation}

The rates and extents of potassium accumulation during glucose respiration, with and without amino acids, are shown in Fig. 2. At $0.998 a_{\mathrm{w}}$, amino acids did not affect the rate but, as $a_{\pi}$ was decreased, increasing non-specific stimulation by amino acids was observed (Fig. 2a). Maximum rates of potassium accumulation were observed at about $0.98 a_{\mathrm{w}}$ and the effect of adding an amino acid to solutions of $a_{w}$ down to 0.97 was to increase linearly the rate of potassium accumulation (Fig. $2 b$ ).

The potassium pool formed during respiration was maximal between 0.98 and $0.97 a_{w}$ in the absence of amino acids (Fig. $2 c$ ), and no uptake of potassium was observed after $2 \mathrm{~h}$ at $0.96 a_{\mathrm{w}}$; clearly amino acids increased the size of the potassium pool at these $a_{\mathrm{w}}$ levels. Although alanine was consistently the least stimulatory amino acid, the effects of the individual amino acids upon potassium pools, as on accumulation rates, were far less specific than upon respiration (Christian \& Waltho, 1966). 

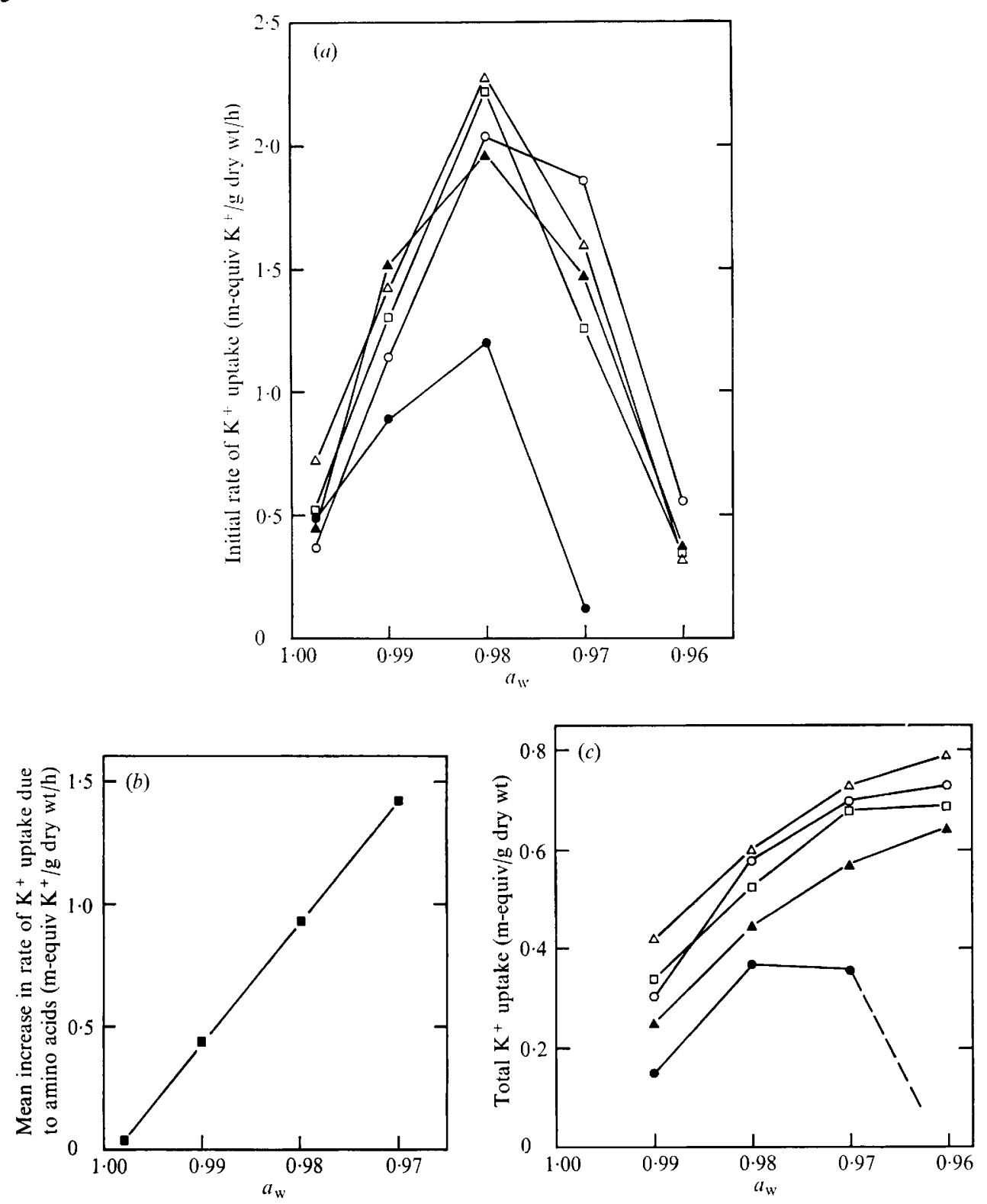

Fig. 2. Effect of amino acids on the water relations of potassium uptake by Salmonella oranienburg during respiration. (a) Initial rates of accumulation of potassium. (b) Increase in rates due to amino acids. (c) Total accumulation of potassium. Amino acid present: $O$, proline; $\Delta$, aspartic acid; $\square$, glutamic acid; $\Delta$, alanine; $\boldsymbol{e}$, nil.

\section{Water relations of amino acid uptake}

The effects of $a_{\mathrm{w}}$ on the accumulation of four ${ }^{14} \mathrm{C}$-labelled amino acids are shown in Fig. 3. In the presence of glucose, the rate of proline accumulation increased greatly as the $a_{w}$ was lowered from 0.998 to 0.99 (Fig. $3 a$ ), but then decreased linearly with a lowering in $a_{\mathrm{w}}$ below 0.98 . In the absence of glucose, the rates of amino acid accumulation were either much lower (at $a_{w}$ values between 0.99 and 0.98 ) or unaltered. At $a_{w}$ values from 0.99 to 

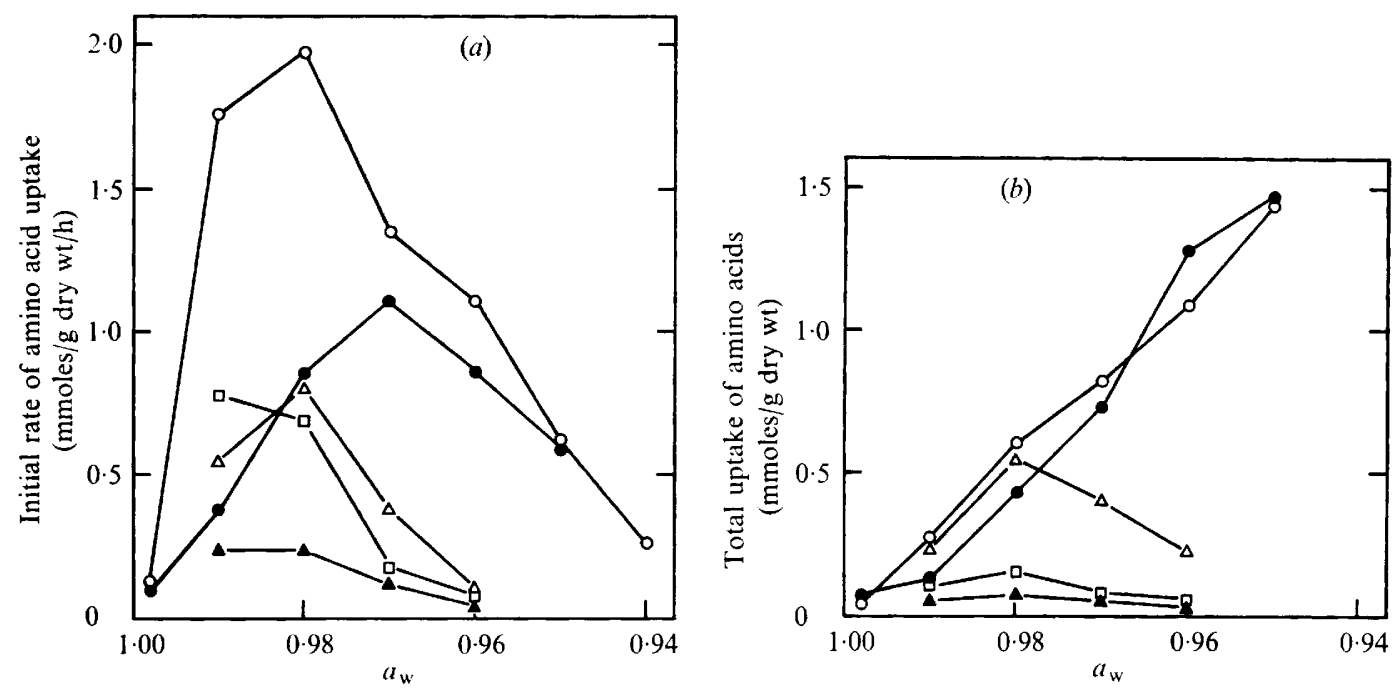

Fig. 3. Water relations of amino acid uptake by Salmonella oranienburg. (a) Initial rates of accumulation. (b) Total accumulation. With glucose present: $\bigcirc$, proline; $\triangle$, aspartic acid; $\Delta$, glutamic acid; $\Delta$, alanine. Without glucose: $\bullet$, proline.

0.96 , rates of uptake of the other amino acids (in the presence of glucose) were substantially lower than those of proline, and were negligible at $0.95 a_{\mathrm{w}}$.

The course of $\left[{ }^{14} \mathrm{C}\right]$ amino acid uptake usually culminated in a well-defined plateau of microbial radioactivity, termed the maximum ${ }^{14} \mathrm{C}$ pool. As will be demonstrated (Fig. 6), proline, and presumably the other amino acids used, was partly metabolized during concentration within the organisms, with consequent redistribution of the ${ }^{14} \mathrm{C}$ label. Fig. $3(b)$ shows the marked differences that existed between proline and the other amino acids in ability to form pools of radioactive solutes at low $a_{\mathrm{w}}$ levels. Pools of ${ }^{14} \mathrm{C}$-labelled solutes formed from $\left.{ }^{[14} \mathrm{C}\right]$ proline increased linearly with reduction of $a_{\mathrm{w}}$ from 0.998 to 0.95 . The other three amino acids produced maximum intracellular ${ }^{14} \mathrm{C}$ pools at $0.98 a_{\mathrm{w}}$, the pool formed from aspartic acid being comparable to that from proline.

Proline accumulation was not affected by chloramphenicol, and in its absence less than I $\%$ of the $\left[{ }^{14} \mathrm{C}\right]$ proline taken up at $0.97 a_{\mathrm{w}}$ was incorporated into material insoluble in cold trichloracetic acid. The data of Fig. 3 were obtained with organisms grown in a complex medium $(\mathrm{BH})$. Organisms harvested from a glucose + inorganic salts medium formed ${ }^{14} \mathrm{C}$ pools from proline which were of similar magnitude to those shown in Fig. $3(b)$, but rates of uptake were lower.

The correlation between the time taken to achieve maximum respiration rate and the time required to form the maximum ${ }^{14} \mathrm{C}$ pool has been discussed above. Equally important is the relationship between ${ }^{14} \mathrm{C}$ pool size and the ultimate respiration rate. At a given $a_{\mathrm{w}}$ an approximately linear relationship existed between the size of the final ${ }^{14} \mathrm{C}$ pool and the maximum $Q_{\mathrm{O}_{2}}$ (Fig. 4). No such relationship existed between potassium pools and respiration rates.

The $a_{\mathrm{w}}$ of the growth medium and of the washing solution influenced greatly the pattern of respiration of Salmonella oranienburg at low $a_{w}$ (Christian \& Waltho, 1966). Growth at high or low $a_{w}$, with or without osmotic shock, did not alter markedly the size of the ${ }^{14} \mathrm{C}$ pool formed subsequently from proline at $0.97 a_{w}$, but aspartic acid uptake was greatly 


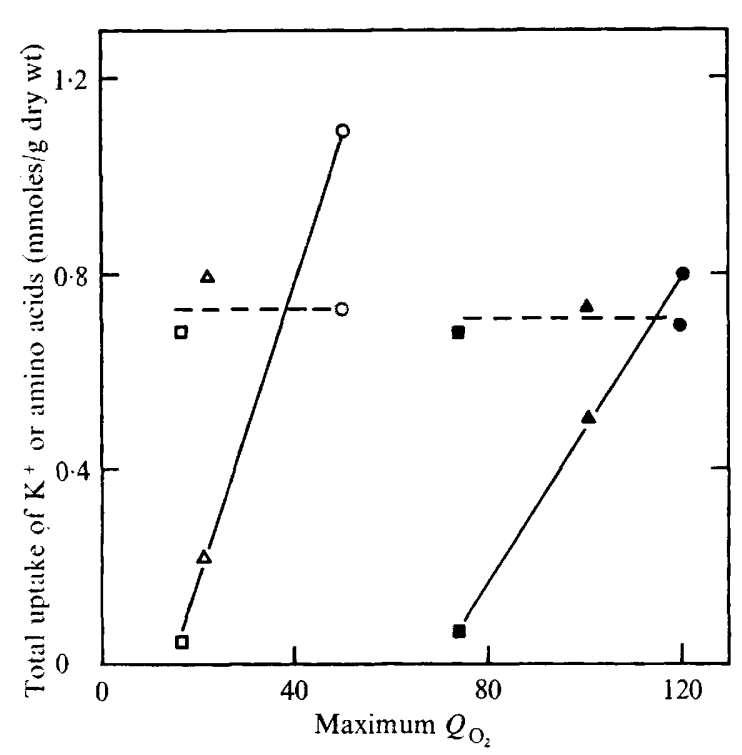

Fig. 4

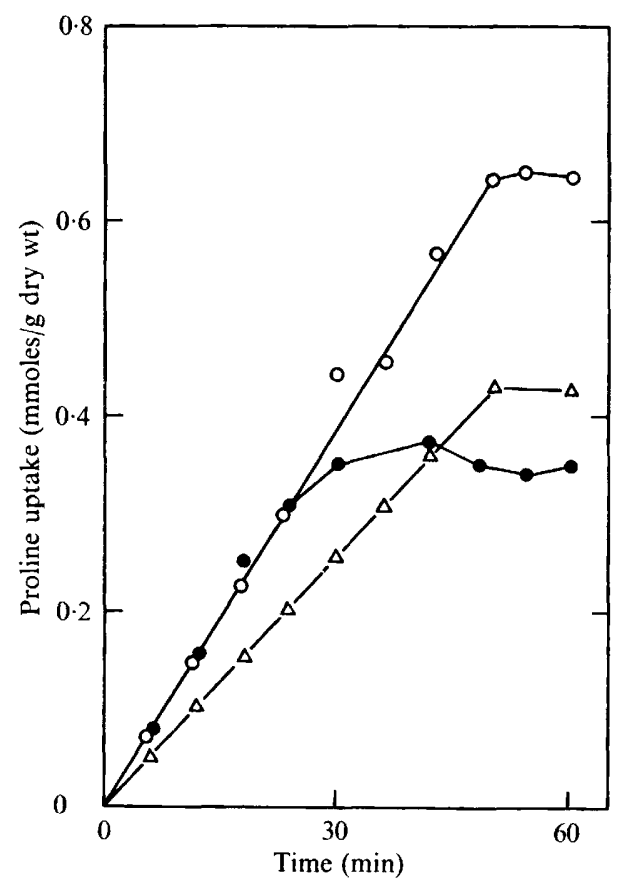

Fig. 5

Fig. 4. Relation between the total potassium and amino acid uptakes and the maximum $Q_{\mathrm{O}_{2}}$ levels attained during glucose respiration in the presence of several amino acids. At $0.97 a_{w}: 0$, proline; $\triangle$, aspartic acid; $\square$, glutamic acid. At $0.96 a_{\mathrm{w}}: \bullet$, proline; $\Delta$, aspartic acid; $\boldsymbol{\omega}$, glutamic acid. Solid lines, amino acid pools; broken lines, potassium pools.

Fig. 5. Specificity of proline accumulation by Salmonella oranienburg during respiration at $0.97 a_{\mathrm{w}}$. $O$, Control; 9 , with mixture of I 9 amino acids; $\triangle$, with azetidine-2-carboxylic acid.

diminished by growth at $0.97 a_{\mathrm{w}}$, and washing the organisms in distilled water almost eliminated their capacity to accumulate either aspartic or glutamic acids.

\section{Specificity of proline uptake}

A mixture of 19 amino acids (each $\mathrm{I} \cdot 67 \mathrm{mM}$ ) did not affect the rate of $\left[{ }^{14} \mathrm{C}\right]$ proline accumulation but decreased the ultimate ${ }^{14} \mathrm{C}$ pool to one-half (Fig. 5). In contrast, the proline analogue azetidine-2-carboxylic acid ( $1.67 \mathrm{~mm}$ ) lowered by one third both the rate and extent of proline accumulation. This analogue, which was oxidized to a negligible extent, greatly stimulated glucose respiration at low $a_{\mathrm{w}}$ values (Christian \& Waltho, 1966).

\section{Metabolism of proline}

The proline that was accumulated during respiration at $0.97 a_{\mathrm{w}}$ was metabolized rapidly so that, during the uptake period, only about one half of the ${ }^{14} \mathrm{C}$ contained within the organisms was in fact proline (Fig. 6). In the final pool about $25 \%$ of radioactivity resided in glutamic acid and $20 \%$ in deaminated substances.

\section{Efflux rates}

Efflux measurements were performed by loading bacteria with $\left[{ }^{14} \mathrm{C}\right]$ proline, washing them in isotonic $\mathrm{NaCl}$ and resuspending in various mixtures. Fig. 7 shows the initial efflux of 


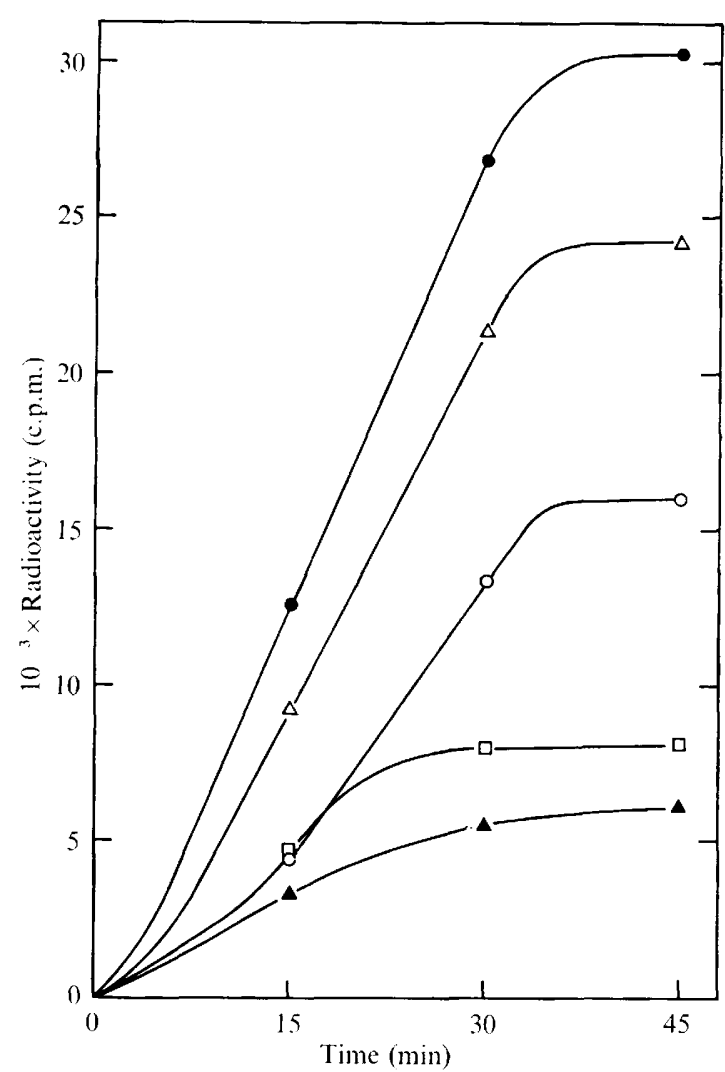

Fig. 6

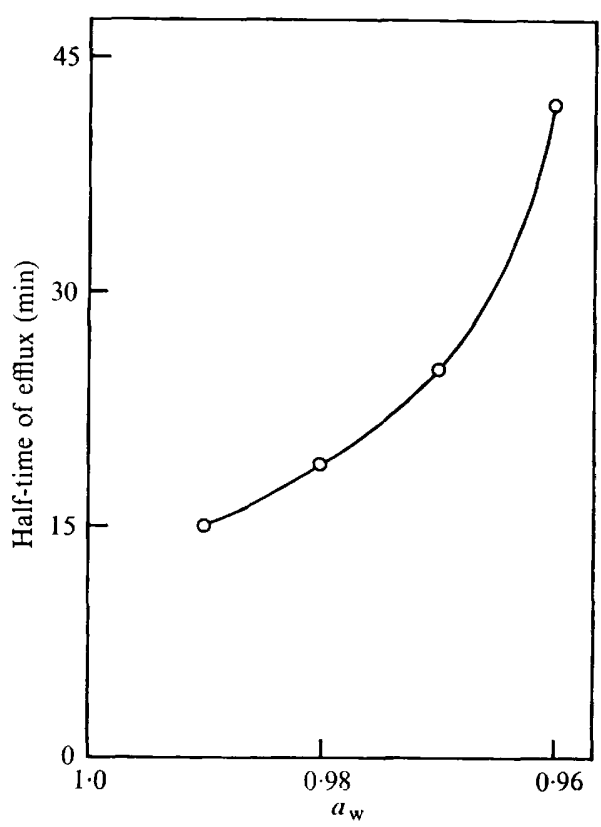

Fig. 7

Fig. 6. Metabolism of $\left[{ }^{14} \mathrm{C}\right]$ proline during accumulation by respiring Salmonella oranienburg at $0.97 a_{\mathrm{w}}$. Bacteria were extracted at intervals and the distribution of radioactivity in the various fractions determined. (-, Total extract; $O$, proline; $\square$, glutamic acid; $\Delta$, proline + glutamic acid; $\Delta$, ninhydrin-negative substances.

Fig. 7. Water relations of efflux of radioactivity from Salmonella oranienburg. Bacteria were loaded with $\left[{ }^{14} \mathrm{C}\right]$ proline during respiration at various $a_{\mathrm{w}}$ levels and resuspended in similar solutions in which [ $\left.{ }^{14} \mathrm{C}\right]$ proline was replaced by $\left[{ }^{12} \mathrm{C}\right]$ proline.

radioactivity from such organisms at four $a_{\mathrm{w}}$ levels. The half-time of efflux almost trebled with decrease of $a_{\mathrm{w}}$ from 0.990 to 0.960 . Efflux rates were measured after proline had accumulated to different levels. Similar half-times were obtained, indicating that initial rates of efflux were the same during, and after completion of, amino acid uptake. After 50 to $80 \%$ of radioactivity had been lost, the rate of efflux changed abruptly. At $0.970 a_{\mathrm{w}}$, for example, the half time of efflux increased from 25 to $49 \mathrm{~min}$.

The half-time of efflux of ${ }^{14} \mathrm{C}$, from bacteria loaded at $0.97 a_{\mathrm{w}}$ with $\left[{ }^{14} \mathrm{C}\right]$ aspartate, into $\left.{ }^{[2} \mathrm{C}\right]$ aspartate was $25 \mathrm{~min}$, the same as found for proline at this $a_{\mathrm{w}}$ level (Fig. 7).

\section{Kinetics of proline accumulation}

The influence of extracellular proline concentration on accumulation rates at three $a_{\mathrm{w}}$ values was studied at concentrations approaching the relatively high level ( $1.67 \mathrm{~mm})$ used previously as a respiratory substrate (Christian \& Waltho, I966). The data are represented by double reciprocal plots in Fig. 8 . The maximum velocity was the same over the range 


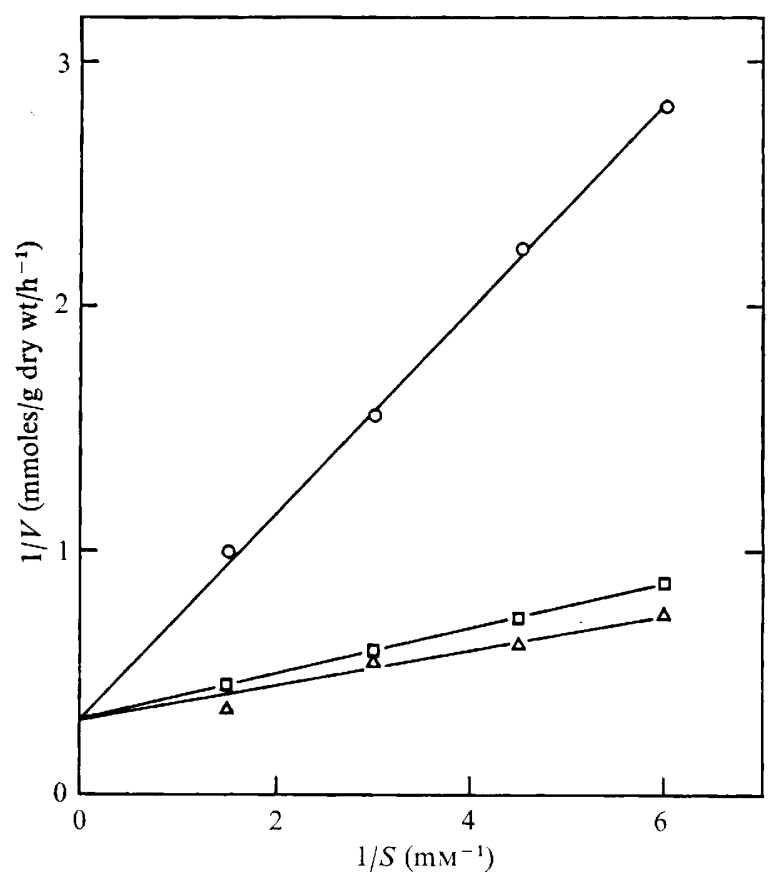

Fig.'8. Reciprocal plots of the initial rates of proline uptake by Salmonella oranienburg as a function of proline concentration. Cells were grown at $0.993 a_{\mathrm{w}}$ and uptake measured at: $\square, 0.99 a_{\mathrm{w}}$; $\triangle, 0.98 a_{\mathrm{w}} ; 0,0.97 a_{\mathrm{w}}$.

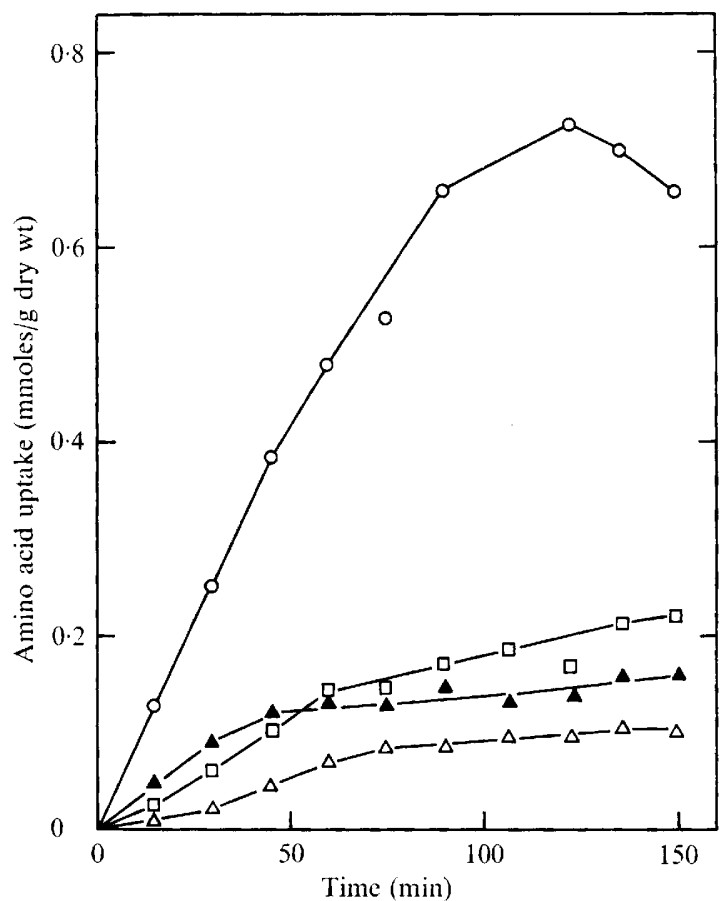

Fig. 9. Uptake of ${ }^{14} \mathrm{C}$-labelled amino acids by Staphylococcus aureus during respiration at $0.94 a_{\mathrm{w}}$. Glucose was the primary substrate. $O$, Proline: $\triangle$, aspartic acid; $\square$, glutamic acid; $\Delta$, alanine. 
0.99 to $0.97 a_{m}$, while the apparent dissociation constants $\left(K_{\mathrm{m}}\right)$ were minimal at about 0.98 and increased greatly with reduction in $a_{w}$.

Extending the range to much lower proline concentrations gave a second linear curve at $0.97 a_{\mathrm{m}}$ with a $K_{\mathrm{m}}$ value of about one-fiftieth and a maximum velocity of one-tenth of those indicated by Fig 8 .

\section{Accumulation of amino acids by Staphylococcus aureus}

Under corresponding conditions of low $a_{w}$, respiration of staphylococci, which are twice as salt-tolerant as salmonellas, was also stimulated by amino acids (Christian \& Waltho, 1966). Proline (and its metabolic products) was accumulated by staphylococci much more rapidly and to much higher levels than were the other three amino acids tested (Fig. 9).

\section{DISCUSSION}

The stimulation of solute uptake by reduced $a_{\mathrm{w}}$ reported here confirms the results of Epstein \& Schultz (1965) for potassium and of Britten \& McClure (1962) for proline. Our results are quantitatively similar to the latter, although obtained under conditions in which no growth or protein synthesis occurred. The effect of amino acids upon potassium uptake is largely non-specific. Proline accumulation at low $a_{w}$ levels is highly specific, and is very resistant to treatments which virtually eliminate accumulation of the other amino acids tested. Kaback \& Deuel (1969) reported that both whole and sonicated membranes of Escherichia coli remained able to take up very high levels of proline from solutions of low $a_{w}$. The suggestion that increase in respiration rate with time at low $a_{\mathrm{w}}$ was related to extensive and concomitant uptake of solute (Christian \& Waltho, 1966) is borne out by the data with proline and with potassium in the absence of amino acids. Oxygen and potassium (or proline) uptake showed no stoichiometry during this period, so they are probably linked by changes in hydration level: if maximum respiration rate requires an appropriately hydrated or turgid cell, the decrease in $a_{w}$ at the beginning of the experiment would dehydrate the bacteria, thus inhibiting respiration, and subsequent solute accumulation would rehydrate the organisms and relieve respiratory inhibition.

Escherichia coli shows an inverse relation between respiration and turbidity over the range 0 to $0.4 \mathrm{M}-\mathrm{NaCl}$ (Henneman \& Umbreit, 1964) and a relationship exists between the formation of a potassium pool and the increase in respiration rate (Miller, Avi-Dor \& Mager, 1964) similar to that reported here (but measured at high $a_{\mathrm{w}}$ in bacteria whose internal solute pools had been depleted by water-washing).

The observation that the half-times of efflux of ${ }^{14} \mathrm{C}$-labelled solutes from $\left[{ }^{14} \mathrm{C}\right]$ aspartateand $\left.{ }^{14} \mathrm{C}\right]$ proline-loaded bacteria, at $0.97 a_{\mathrm{w}}$, were similar suggests strongly that the much larger pool formed from proline at this $a_{w}$ results from a greater influx, not a lesser efflux, of that amino acid. Epstein \& Schultz (1965) concluded that the rapid accumulation of potassium by Escherichia coli following hypertonic shock resulted also from increased influx rather than reduced efflux.

The conditions under which proline stimulates respiration of Salmonella oranienburg resemble those under which choline stimulates respiration of a moderately halophilic bacterium (Rafaeli-Eshkol, 1968). However, two major differences exist: (i) choline uptake continues throughout the constant as well as the accelerating phase of respiration, approximately 1o $\mu$ mol oxygen being utilized per I $\mu$ mol choline accumulated; (ii) the pools of labelled substrates formed from choline uptake are only one-hundredth those formed from proline.

When the initial values for potassium and amino acid pools are added to the amounts 
accumulated by Salmonella oranienburg during respiration at the various $a_{\mathrm{w}}$ levels, the total potassium pool is the larger down to $0.97 a_{\mathrm{w}}$. At $0.96 a_{\mathrm{w}}$ the 'total proline pool' (which includes all TCA-soluble ${ }^{14} \mathrm{C}$-labelled products of $\left[{ }^{14} \mathrm{C}\right]$ proline metabolism) has become the greater. These data resemble those for Staphylococcus aureus (Christian \& Waltho, 1964), in which the amino acid pool exceeded the potassium pool in cells grown at $a_{\mathrm{w}}$ levels below about $0.9 \mathrm{I}$. For both organisms, the change in predominant solute occurred at an external salt concentration close to two-thirds of the maximum permitting growth.

\section{REFERENCES}

Britten, R. J. \& MCClURE, F. T. (1962). The amino acid pool in Escherichia coli. Bacteriological Reviews 26, 292-335.

Christian, J. H. B. (1955). The influence of nutrition on the water relations of Salmonella oranienburg. Australian Journal of Biological Sciences 8, 75-82.

Christian, J. H. B. \& Waltho, J. A. (1964). The composition of Staphylococcus aureus in relation to the water activity of the growth medium. Journal of General Microbiology 35, 205-213.

Christian, J. H. B. \& WALtho, J. A. (1966). Water relations of Salmonella oranienburg; stimulation of respiration by amino acids. Journal of General Microbiology 43, 345-355.

EpsteIN, W. \& SCHULtZ, S. G. (1965). Cation transport in Escherichia coli. V. Regulation of cation content. Journal of General Physiology 49, 221-234.

HENNEMAN, D. H. \& UMBREIT, W. W. (1964). Influence of the physical state of the bacterial cell membrane upon the rate of respiration. Journal of Bacteriology 87, 1274-1280.

KABACK, H. R. \& Deuel, T. F. (1969). Proline uptake by disrupted membrane preparations from Escherichia coli. Archives of Biochemistry and Biophysics 132, 11 8-129.

Miller, S., Avi-Dor, Y. \& MAGER, J. (1964). Studies on the mechanism of potassium-stimulated respiration in Escherichia coli. Journal of General Microbiology 36, 123-131.

RAFAELI-ESHKOL, D. (1968). Studies on halotolerance in a moderately halophilic bacterium. Effect of growth conditions on salt resistance of the respiratory system. Biochemical Journal rog, 679-685. 